\title{
AS ALHAJAS Y ORNAMENTOS LITÚRGICOS DE LA CAPILLA DE LOS DUQUES DE MONTEMAR EN LA BASÍLICA DEL PILAR DE ZARAGOZA ${ }^{1}$
}

MARÍA JOSEFA TARIFA CASTILLA

Instituto de Investigación en Patrimonio y Humanidades. Universidad de Zaragoza mjtarifa@unizar.es

Resumen: El presente artículo da a conocer y estudia el ajuar litúrgico proporcionado por María Magdalena Carrillo de Albornoz, II duquesa de Montemar, para la capilla de patronato que poseía desde 1761 en la Basílica del Pilar de Zaragoza bajo la titularidad de San Joaquín. Esta aristócrata dotó la capilla con los ornamentos textiles y piezas de orfebrería necesarios para el servicio del culto, como refieren los inventarios de 1789 , 1804 y 1873 . Entre las alhajas de plata destacaban un cáliz renacentista y un relicario barroco con las armas de los Montemar, que han sido localizados en la sacristía mayor del mismo templo del Pilar.

Palabras clave: Duques de Montemar / Basílica de Nuestra Señora del Pilar / Zaragoza / siglo XVIII / platería / ornamentos litúrgicos.

\section{JEWELRY AND THE LITURGICAL TROUSSEAU OF THE CHAPEL OF THE DUKES OF MONTEMAR IN THE BASILICA OF OUR LADY OF THE PILLAR OF SARAGOSSA}

Abstract: This article deals with the study of the liturgical trousseau provided by Maria Magdalena Carrillo de Albornoz, II Duchess of Montemar, for the patronage chapel of saint Joachim she had owned since 1761 in the Basilica of Our Lady of the Pillar of Saragossa. This aristocrat endowed the chapel with the textile ornaments and pieces of goldsmithing necessary for the service of the cult, as it's referred in the inventories of 1789, 1804 and 1873. Among the silver jewels stood out a Renaissance chalice and a baroque reliquary with the coat of arms of the Montemar, which are located in the main sacristy of the same temple of Pillar.

Key words: Dukes of Montemar / Basilica of Our Lady of the Pillar / Saragossa / 18th century / silverwork / liturgical clothes.

\section{La dotación del ajuar litúrgico de la capilla de San Joaquín por la II duquesa de Montemar: el inventario de 1789}

María Magdalena Carrillo de Albornoz y Antich (1707-1790), nació en El Viso de Alcor (Sevilla) en septiembre de 1707, fruto del matrimonio formado por el distinguido militar José Carrillo de Albornoz y Montiel (1671-1747) y de Isabel Francisca de Antich y Antich. Su progenitor fue uno de los militares y políticos más relevantes del reinado de Felipe V, entre cuyas gestas bélicas destacan la conquista de Orán en 1732 o la batalla de Bitonto (25 de mayo de 1734), cuyo triunfo sobre los austríacos permitió coronar a Carlos III rey de Nápoles y Sicilia, servicio por el que Carrillo de Albornoz fue premiado con el nombramiento de Virrey y Ca-

* Fecha de recepción: 15 abril de 2019 / Fecha de aceptación: 21 de junio de 2019.

1 Investigación desarrollada en el marco del Grupo de Investigación de Referencia Vestigium (H19_17R), financiado por el Departamento de Innovación, Investigación y Universidad del Gobierno de Aragón y cofinanciado por el programa operativo Feder Aragón 2014-2020 "Construyendo Europa desde Aragón". 
pitán General de Sicilia y con la Grandeza de España de primera clase sobre el título de duque de Montemar. ${ }^{2}$ María Magdalena contrajo nupcias el 31 de agosto de 1729 en la Puebla de Cazalla (Sevilla) con José Lorenzo Dávila Tello de Guzmán y Medina, III conde de Valhermoso, ${ }^{3}$ con el que tuvo tres hijos, José Félix ( $†$ 1748), María Josefa del Carmen y Francisca María. Tras el fallecimiento de José Carrillo de Albornoz en Madrid, el 26 de junio de 1747, María Magdalena heredó de su padre el título nobiliario del ducado de Montemar.

En 1760 el monarca Carlos III decidió honrar la memoria de algunos de los más destacados militares que habían prestado sus servicios a la corona española, encargando la ejecución de sus mausoleos a costa de la real hacienda, como fue el caso del monumento funerario del I duque de Montemar, cuyos restos mortales reposaban en la iglesia del noviciado de la Compañía de Jesús. Probablemente, este honorable gesto del rey hacia la persona de José Carrillo de Albornoz llevó a la II duquesa de Montemar a requerir a fines de dicho año al cabildo del templo de Nuestra Señora del Pilar de Zaragoza ${ }^{4}$ la concesión del patronato de una de las capillas en la que poder disponer el sepulcro de su progenitor, solicitud que fue atendida mediante la entrega de la de San Joaquín (hoy de San Braulio). ${ }^{5}$ La donación de este espacio fue protocolizada el 16 de enero de $1761,{ }^{6}$ con derecho de enterramiento para los miembros de su linaje, cedida con motivo de "la distinguida nobleza de su casa, como su fervorosa devocion a Maria Santisima del Pilar, de la que se conservan algunas memorias en alhaxas primorosas que oy existen dadas por el Excelentisimo Señor Duque de Montemar".7 Sin embargo, María Magdalena finalmente recibió el 7 de agosto de 1761 la capilla del Santo Cristo, que a partir de entonces estuvo bajo la advocación de San Joaquín, ${ }^{8}$ abierta al lateral de la nave norte o del Evangelio, sobre cuyo arco de acceso se dispusieron las armas de José Carrillo de Albornoz, como signo visible del patronato ejercido en la misma por los duques de Monte$\operatorname{mar}^{9}$ (Fig. 1). En la pared interior izquierda de la capilla se colocó en junio de 1766 el sepulcro del I duque de Montemar, diseñado en 1764 por el capitán de ingenieros Esteban de Peñafiel y en el que participó el escultor aragonés Lamberto Martínez Lasanta. ${ }^{10}$

A su vez, María Magdalena Carrillo de Albornoz quiso vincular la memoria de su linaje con esta capilla de San Joaquín, habilitando bajo la misma el panteón familiar de los duques de Montemar, al igual que sucedía con otra destacada capilla de patronazgo particular existente en la basílica mariana del Pilar con uso funerario, la de San José, cuya titularidad ostentaban los marqueses de Villaverde. ${ }^{11}$ El proyecto recayó en manos del artista zaragozano Joaquín Gracián, quien en marzo de 1773 presentó dos propuestas a María Magdalena, si bien finalmente el panteón no se llevó a cabo. ${ }^{12}$

Los titulares de las capillas de patronato no solo se ocupaban de abastecerlas con los bienes y recursos económicos necesarios para la manutención de los capellanes que atendían el culto y la celebración de las misas acordadas en beneficio de sus almas y las de sus familiares, sino que además se preocupaban de dotarlas con el ajuar litúrgico necesario. María Magdalena Carrillo de Albornoz se comprometió en la escritura de cesión del patronato de la capilla de San Joaquín, rubricada el 14 de febrero de 1761, a proveerla con "un retablo correspondiente a la grandeza de su persona, y magnificencia y hermosura del templo, en la forma que el sitio lo permita", además de con una lámpara y los enseres precisos para la celebración del culto, dotándola con una renta anual de 790 reales. ${ }^{13}$ Por ello, en octubre de 1766

\footnotetext{
2 FELICES DE LA FUENTE, Mª del Mar, 2013, pp. 162-163. ESCRIBANO BERNAL, Francisco, 2018, n 139, pp. 89-94.

3 ALONSO DE CADENAS Y LÓPEZ, Ampelio; CADENAS Y VICENT, Vicente de, 1993, p. 588.

${ }^{4}$ Sobre la construcción del nuevo templo barroco (1680-1765), véase ANSÓN NAVARRO, Arturo; BOLOQUI LARRAYA, Belén, 1982, pp. 259-270. BOLOQUI LARRAYA, Belén; ANSÓN NAVARRO, Arturo, 1987, pp. 243-286. MARÍAS, Fernando, 2017, pp. 108-141.

${ }^{5}$ Archivo Capitular del Pilar de Zaragoza [A.C.P.Z.], Actas Capitulares, año 1760, f. 109.

${ }^{6}$ BOLOQUI LARRAYA, Belén, 1983, vol. 1, p. 447. BOLOQUI LARRAYA, Belén, 1983, vol. 2, doc. 390, pp. 263-265.

7 A.C.P.Z., Actas Capitulares, año 1761, ff. 12-23.

8 A.C.P.Z., Actas Capitulares, año 1761, f. 103. BOLOQUI LARRAYA, Belén, 1983, vol. 2, doc. 391, p. 265.

9 BOLOQUI LARRAYA, Belén, 1983, vol. 1, p. 181. Sobre la descripción del escudo, véase RINCÓN GARCíA, Wifredo, 2009, p. 46.

10 TARIFA CASTILLA, Ma Josefa, 2018 a, pp. 645-656. SANZ DE MIGUEL, Carlos, 2018, vol. 19, pp. 213-243.

11 RINCÓN GARCÍA, Wifredo, 2009, pp. 54-60.

12 TARIFA CASTILLA, Ma Josefa, 2018 b, nº 33, pp. 333-338.

13 A.C.P.Z., Actas Capitulares, año 1761, ff. 12-23. Archivo Histórico de la Nobleza [A.H.NOB.], Baena, C.364, D.42-60.
} 
pidió autorización para colgar en la capilla una lámpara similar a las dispuestas en la Santa Capilla del mismo templo, ${ }^{14}$ solicitud que fue atendida. ${ }^{15}$

Unos años después, el 20 febrero de 1789, Manuel Bellostas, apoderado de la II duquesa de Montemar, se reunió en la sacristía de la capilla de San Joaquín, adosada al lateral derecho de la estancia, con Juan Blas Terrén, presbítero capellán de la misma y Antonio Carbonell, su capiller o capillero, con objeto de realizar el inventario de "todos los muebles, alaxas, jocalias, ropa blanca, plata y demas que existe en dicha Sachristia", cuya transcripción literal recogemos en el apéndice documental. ${ }^{16} \mathrm{En}$ primer lugar, se reseñaron las "alaxas de madera" o mobiliario emplazado en la capilla, como una tarima labrada para colocar en el altar, "un contramarco ancho moldeado" pintado de color jaspe, o una mesa policromada y dorada en la que se disponían las vinajeras y el ajuar necesario para el servicio del culto. Seguidamente se registraron los objetos lignarios de la sacristía, apartado en el que se incluyeron "un juego completo de sacras con su lababo y evangelio de talla plateada y bruñida con su Christo plateado al remate de ellas y dos candelabros pequeños plateados y lisos".

Por lo que respecta a las "alajas de barro y otras", se anotaron piezas tan diversas como un plato de Aranda con un juego de vinajeras de cristal, un hostiario de hojalata y tintero del mismo material para la sacristía, una campanilla de metal para uso diario y varios libros litúrgicos, como "un misal grande de impresion de Antuerpia enquadernado en pasta con sus manecillas y rexistros y contraforros de tafilete o badana colorada y otra negra", es decir, un volumen editado en Amberes y con una encuadernación muy cuidada, y otro cuaderno de tapas negras para las misas de réquiem o difuntos.

En el caso de los textiles, que fueron clasificados en dos tipos, o de ropa blanca o de seda, el inventario recoge tanto la indumentaria religiosa con la que se revestiría el eclesiástico responsable de la liturgia en la capilla de San Joaquín, formada por el alba, el cíngulo, el amito y la casulla, detallando su color, tipo de tela y decoración, además del ro-

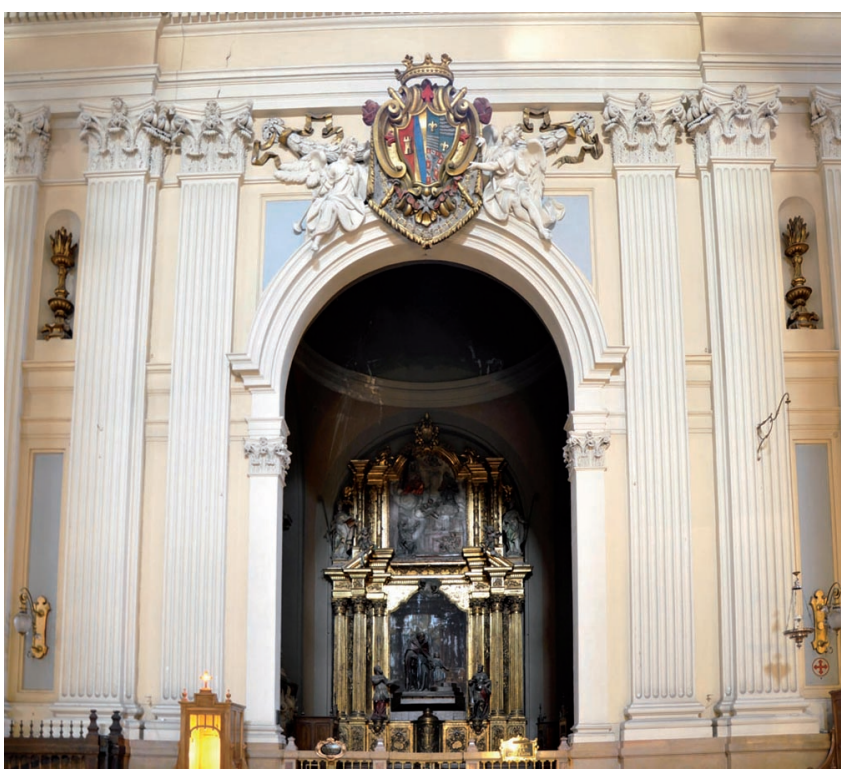

Fig. 1. Capilla de San Joaquín en la basílica de Nuestra Senora del Pilar de Zaragoza. Fotografía: Ma Josefa Tarifa Castilla. Cabildo Metropolitano de Zaragoza.

quete utilizado por el capillero, como los ornamentos y ajuar textil empleados en el servicio de los divinos oficios. ${ }^{17}$ En el grupo de la ropa blanca se referenciaron, en el caso de las vestimentas, nueve albas -dos de ellas con encaje muy ancho-, catorce amitos correspondientes a las telas de las albas con tres juegos de cintas, dos cíngulos de hilo blanco fino de Génova y dos roquetes con encaje para el uso del capiller. Por lo que respecta a los ornamentos de altar, se contabilizaron seis juegos de manteles, la mayor parte de ellos con encaje, ocho juegos de corporales con encaje en sus orillas, tres hijuelas pequeñas del mismo tejido para el "sobrecaliz" o cubrecáliz y otras dos de seda con galones de oro, treinta y dos purificadores, doce toallas para vinajeras, cuatro toallas grandes para el lavado de las manos, además de un saco de estopa y cáñamo para llevar la ropa a la colada.

En cuanto a las vestimentas de seda, se hallaron diez juegos de casullas completos, concretamente,

\footnotetext{
${ }^{14}$ En el inventario de la sacristía mayor del templo del Pilar de 1758, se anotaron "treinta y una lámparas de plata, que arden en el Quadro de la Sta Capilla". A.C.P.Z., Armario 6, Cajón 6, Ligamen 2, n 10. Libro de inventario de la Plata, relicarios, Jocalias, ornamentos y demas cosas de la sacristia mayor de la S. Angca y Apca Igla de Nra Sra del Pilar de Zaragoza. Se hizo año 1758, f. 117. Años después, en 1785 había 28 lámparas rodeando la Santa Capilla. Ibidem, f. 118.

15 A.C.P.Z., Junta de Hacienda, año 1766, f. 136.

${ }^{16}$ A.H.NOB., Baena, C.364, D.42-60. Apéndice Documental $n^{\circ} 1$.

17 Sobre este tipo de ornamentos textiles en Aragón, véase ÁGREDA PINO, Ana, 2001.
} 
cinco de damasco, de diferentes tonos, rojo, blan$\mathrm{co}$, verde y morado para utilizarlos en los diferentes tiempos litúrgicos, además de otro negro, cada uno de ellos con su estola, manípulo, velo para cubrir el cáliz y tres bolsas de corporales embellecidas con galones y con el forro dorado, como se detalla en el inventario; y los otros cinco juegos de casullas de espolín, asimismo de diferentes tonalidades, con elaborados bordados de flores, cada uno con el velo para el cáliz y la bolsa de corporales. Además, se anotaron otras cuatro casullas, con el velo y bolsa de corporales correspondientes, especificando igualmente su tonalidad, tejido y tipo de confección, y tres cíngulos de seda de diferentes colores. El apartado de los tejidos de seda concluía con un frontal de lienzo pintado para adornar la parte anterior del altar y una cortina de "olandilla" para cubrir el altar.

En la sección de las "alaxas de plata" se recogieron las diferentes piezas empleadas en la celebración de los divinos oficios, si bien, la escueta anotación, en la que apenas se refiere el material utilizado, peso y en ocasiones una descripción generalizada de su forma, no permite afinar la posible cronología, técnica empleada, o si contaban con marcas de localidad y autor, lo que hubiese permitido identificar el lugar en el que fueron realizadas y el platero que las acometió. Excepcionalmente, uno de los vasos litúrgicos fue registrado con mayor detalle, descrito como "un caliz de plata grabado y labrado con sus efigies al pie de medio relieve de los evangelistas y otras, y labor colada (sic) por junto a la copa, todo dorado", con su correspondiente patena y cucharilla de plata con una cinta rosa, el cual se guardaba en una caja colorada. También había otro cáliz de plata lisa con su patena, conservado igualmente en un estuche de tonalidad roja, otra cucharilla, un hostiario grabado, un par de vinajeras grandes, una palmatoria, una campanilla, una servilleta grabada de forma ovalada, una cruz grande de plata con un crucificado de bronce dorado, además de una lámpara de plata dispuesta en la capilla, seguramente la que adquirió en 1766 la II duquesa de Montemar, como se ha referido anteriormente.

El inventario concluyó con un apartado en el que se alistaron "otras alaxas", desde un alba de muselina de flores adornada con encajes muy exqui- sitos de Flandes, con su amito a juego; piezas de madera, como seis candelabros grandes tallados $y$ plateados, y un pie grande decorado y plateado en el que colocar la cruz de plata aludida más arriba; hasta otros enseres de distintos materiales, como un platillo ovalado y labrado de peltre fino de Inglaterra con sus vinajeras del mismo material, y un atril de concha con sus planchas de plata. Incluso se refirió aquí "el lavatorio" de la sacristía, "de piedra jaspe con rebutidos", que se sigue conservando en la actualidad (Fig. 2).

En esta sección que reunía objetos de variada naturaleza, también se catalogaron obras de relevancia artística. Por ejemplo, un relicario de plata "de Sn. Joaquin, Sta. Ana y Sn. Felipe Neri que sera de peso como de unas diez onzas y a la espalda de ella ay una chapa con las armas de la Casa de su Ex $x^{a}$ y todo con su caxa forrada en badana encarnada", por tanto, una pieza de orfebrería que tenía la excepcionalidad de ser la única de todo el ajuar litúrgico en la que se grabaron las armas de los Montemar. Asimismo, en este apartado se aludió a dos pinturas existentes en la sacristía de la capilla. En primer lugar, la "efigie de la Cara de Dios de Jaen, con su christal, guarnecido el quadro en moldura azul con sobrepuestos de plata, tiene su caxa de madera forrada en bayeta colorada para su guarda". Es decir, se trataba de una copia del cuadro con la vera efigie de Jesús conservada en la catedral jiennense, ${ }^{18}$ reflejo de la devoción que mostraban los miembros de este linaje de los Montemar hacia dicha imagen. ${ }^{19}$ En segundo lugar, el retrato del duque de Montemar dispuesto en la sacristía "con su marco dorado, y la inscripcion de piedra marmol vajo del mismo y se hallan encarcelados en la pared". Este lienzo, como se ha dado a conocer en un reciente estudio, fue encargado por la II duquesa de Montemar al pintor flamenco Juan Andrés Merklein, quien efigió a José Carrillo de Albornoz en un retrato de medio cuerpo, que concluyó para la primavera de 1779. ${ }^{20}$

El registro de 1789 concluyó con la indicación del capillero Carbonell, quien refirió que en la casa de la viuda de Miguel López Fernández de Heredia, conde de Bureta, se conservaba una alfombra de diferentes colores perteneciente a la capilla de San Joaquín que se ponía el día de la festividad del titular, ya que dado su gran tamaño no podía guardarse en la sacristía.

\footnotetext{
18 MARTíNEZ ROJAS, Francisco Juan, 2012, pp. 14-17.

19 De hecho, unos años después, en 1814, la entonces duquesa de Montemar, como voto por la liberación del monarca Fernando VII, regaló un lazo de brillantes que coronó el cuadro hasta 1936, cuando la imagen fue sustraída de la catedral. MARTÍNEZ ROJAS, Francisco Juan, 2012, p. 17.

20 TARIFA CASTILLA, Ma Josefa, 2018 b, pp. 341-344.
} 


\section{El convulso siglo XIX: el registro de 1804 y los listados del capiller Ripoll}

Tras el fallecimiento de María Magdalena Carrillo de Albornoz, acaecido en Madrid el 10 de noviembre de 1790, la sucesión del título del ducado de Montemar recayó en su nieto, Antonio María Ponce de León Dávila Carrillo de Albornoz (17571826), quien recibió todas las posesiones ligadas al mismo, como el patronato de la capilla de San Joaquín del templo del Pilar de Zaragoza, del que tomó posesión el 26 de agosto de 1791 a través de su apoderado, el referido Manuel Bellostas. ${ }^{21}$

Unos años después, en 1804, con ocasión de la muerte del capellán Juan Terrén, se volvió a registrar en presencia de Bellostas las joyas, alhajas y demás objetos de culto pertenecientes a la capilla de San Joaquín. El inventario es prácticamente similar al realizado en 1789 , manteniendo incluso los mismos apartados. Por lo que respecta a las "alhajas de madera", se especificó que la tarima o gradas grandes pintadas de varios colores se colocaban encima de la mesa del altar el día de la festividad de San Joaquín. Por su parte, el misal grande impreso en Amberes catalogado anteriormente, había perdido las manecillas, motivo por el que probablemente se había adquirido otro publicado en Madrid.

En lo referente a la ropa blanca, había aumentado el número de prendas con respecto al inventario de 1789. Así, se contabilizaron diez albas, además del alba de muselina de flores con encaje ancho de Flandes y su amito de la misma tela conservado en una caja de madera; diecinueve amitos, con tres juegos de cintas -dos azules y uno encarnado-; diversos cíngulos; cuarenta y dos purificadores y dos manteles más con encaje para engalanar la mesa del altar. En cuanto a las vestimentas de seda, se anotaron tanto los diez juegos de casullas completos, como las otras cuatro casullas de distintos colores recogidas en el listado de 1789, añadiéndose además otra casulla de espolín de color encarnado con flores, un frontal de damasco negro para el día de difuntos y dos paños morados para cubrir los crucifijos durante el tiempo de Pasión.

En la sección de las alhajas de plata, se enumeraron las mismas piezas que en el inventario ante-

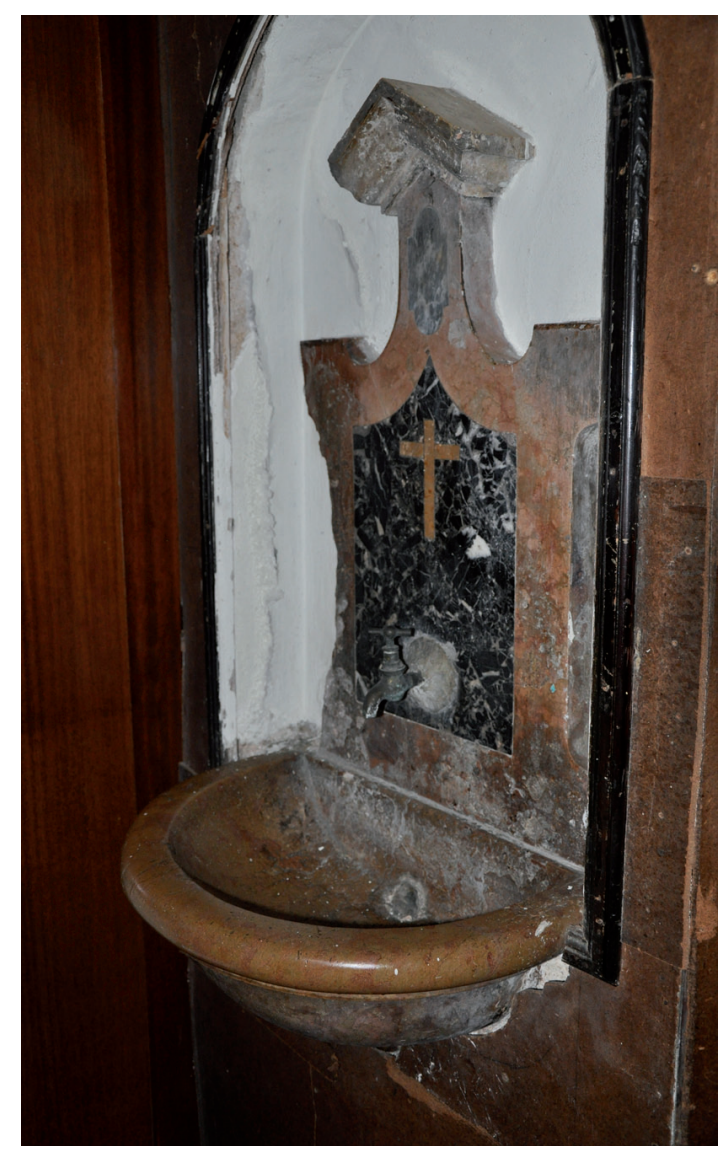

Fig. 2. Aguamanil de la sacristía de la capilla de San Joaquín. Fotografía: Ma Josefa Tarifa Castilla. Cabildo Metropolitano de Zaragoza.

rior de fines del siglo XVIII, a excepción de una cucharilla de plata para poner el agua en el cáliz, que ya no aparece registrada. En cambio, se anotaron dos "bujías" o candeleros de plata que no estaban referidos anteriormente, probablemente porque pasaron a formar parte del ajuar litúrgico de la capilla después de 1789.22

Tras la defunción de Antonio María Ponce de León en 1826, el patronato de la capilla de San Joaquín lo ostentó su nieto, Vicente Pío Osorio de Moscoso Ponce de León (1801-1864). En los años centrales de la década de 1830, bajo el gobierno

21 A.H.NOB., Baena, C.283, D.180.

22 La II duquesa de Montemar había expresado su deseo en septiembre de 1790, unos meses antes de fallecer, de que los candelabros de plata que le había regalado su hija Francisca María, condesa de Torrepalma, se entregasen a esta capilla de San Joaquín del Pilar de Zaragoza. Con los datos que disponemos al presente no podemos confirmar que dichos soportes de velas con diferentes brazos sean las mismas piezas argénteas referidas en el inventario de 1804, teniendo en cuenta además que en este último listado se alude a candeleros, y no a candelabros. 
del ministro Mendizábal, se pusieron en marcha las medidas desamortizadoras (1836-1837), por las cuáles se declararon bienes nacionales las propiedades de las órdenes religiosas, solo del clero regular, con objeto de venderlas en pública subasta y con los beneficios económicos reducir la deuda del Estado. En este contexto, la Diputación Provincial de Zaragoza ordenó en 1837 realizar un expediente de valoración de las alhajas de plata existentes en las iglesias de la capital.

Cuando se evaluaron las alhajas que había en la capilla de San Joaquín del templo del Pilar, Joaquín Ripoll, músico que desde 1812 se encargaba del cuidado de la misma como capillero, ${ }^{23}$ manifestó que eran de propiedad del duque de Montemar. ${ }^{24}$ A su vez, Ripoll envió el 30 de agosto de 1837 una carta al administrador de los bienes del duque, informándole del peligro de que dichas piezas fuesen incautadas. ${ }^{25}$ A este escrito respondió Salvador Enrique Calvet, que desde comienzos del mes de septiembre de 1837 había sido nombrado responsable del gobierno de las casas y rentas del duque de Montemar, ${ }^{26}$ por medio de una epístola rubricada en Madrid el 16 de septiembre del mismo 1837, indicándole "que por todos medios evite v. que nadie sea quien quiera se apodere de las expresadas alhajas y efectos (...). Tambien espero me remita v. copia del inventario cuanto exista en su poder, propio del Sr. Duque, para que en la direccion de su casa obre los efectos oportunos". 27

Sin embargo, Ripoll no contestó a las indicaciones expresadas en esta misiva de 1837 hasta dos años después, cuando remitió una carta desde Zaragoza, fechada el 11 de abril de 1839, en la que informaba a Enrique Calvet "que los hornamentos y limpieza de ropa blanca de dicha capilla estan a cargo del Illmo Cabildo desde 1828, corriendo este con el reemplazo de alguna falta, y composturas", dado que el duque dotaba a la capilla con una pen- sión de 240 reales de vellón anuales para proveerla de todo lo necesario a su mantenimiento y culto. Además, adjuntó una nota en la que refirió sucintamente la plata perteneciente a la capilla, que custodiaba en su casa de la calle Cedacería, a saber: "Una Cruz de plata con su Crucifijo dorado / Un plato con sus dos vinajeras de plata / Un Hostiero de plata / Una Campana de plata / Un Caliz de plata sovre dorado / Iden, otro Caliz de plata / La Reliquia de San Joaquin de plata / Dos Bujias de plata / Dos patenas de plata".28 Adviértase que en este listado no aparecen otras piezas argénteas recogidas en el inventario anterior de 1804, como la palmatoria o la servilleta ovalada.

A mediados de 1843 Ripoll, a sus 73 años, remitió otra carta al administrador, informándole del impago de las pensiones que la obrería del Pilar le debía de los años anteriores por el cuidado de la capilla de San Joaquín, sueldo que no había percibido dado que desde la casa del ducado de Montemar no se había enviado la dotación anual establecida. En dicho escrito adjuntó un listado con las piezas textiles que había en la sacristía de la capilla, sin describirlos, agrupándolos, en primer lugar, por casullas coloradas, blancas, moradas, verdes y negras, expresando que el cabildo había repuesto cuatro de ellas ante el mal estado de conservación de las existentes. Asimismo, inventarió bajo el epígrafe de ropa blanca las albas, amitos, purificadores, corporales, toallas de vinajeras y de lavatorio, un frontal para el altar y otro para el día de difuntos y las sobrepellices. También refirió que los "candeleros de madera plateados" estaban muy estropeados, por lo que desde hacía tiempo tenía que pedir prestados otros para utilizarlos el día de la festividad de San Joaquín. Finalmente, hizo saber que los "calajes" o armarios destinados a guardar los ornamentos estaban podridos, sobre todo la parte de la madera que estaba en contacto con el suelo de la sacristía, por lo que eran inservibles. ${ }^{29}$

\footnotetext{
${ }^{23}$ Ripoll informó que desempeñaba sus funciones de capiller desde al menos 1810 y, por ello, cuando en 1812 durante la Guerra de la Independencia dos soldados franceses entraron en la sacristía de la capilla de San Joaquín con objeto de sustraer las alhajas existentes en la misma, él se opuso, consiguiendo que fracasaran en su intento. A.H.NOB., Baena, C.78, D.21-34, ff. 7r-7v.

${ }^{24}$ A.H.NOB., Baena, C.78, D.21-34, f. 11r.

${ }^{25}$ A.H.NOB., Baena, C.78, D.21-34.

26 A.H.NOB., Baena, C.312, D. 224.

27 A.H.NOB., Baena, C.78, D.21-34, ff. 10r-10v.

${ }^{28}$ A.H.NOB., Baena, C.78, D.21-34. Estos mismos objetos, además de una palmatoria de plata, fueron registrados, con su peso en onzas y cuantía de reales de vellón, en el inventario de alhajas de las iglesias de Zaragoza remitido en octubre de 1837 a la Diputación Provincial de Zaragoza, tal y como se anotó en el Imbentario de las alhajas de oro, plata y pedrería existentes en el St. Templo Metropolitano de Nuestra Señora del Pilar de Zaragoza. Archivo Capitular de la Seo de Zaragoza [A.C.S.Z.], Apéndice al inventario formado en 1873.

${ }^{29}$ A.H.NOB., Baena, C.78, D.21-34, ff. 7r-8v.
} 


\section{El inventario de 1873}

En el último tercio del siglo XIX se realizó un completo inventario del templo de Nuestra Señora del Pilar de Zaragoza, en el que hemos localizado un detallado registro con el exorno artístico y ajuar litúrgico existente en la capilla de San Joaquín y su sacristía en el año de $1873 .^{30}$ La relación comenzaba con el retablo barroco dieciochesco que desde 1851 presidía el altar de la capilla, procedente de la iglesia del convento franciscano de San Cristóbal de Tauste, en el que se sustituyó el lienzo de San Francisco por el grupo escultórico de San Joaquín y la Virgen Niña, obra de Antonio Palao y Marco, ante una perspectiva del templo que pintó sobre tabla Mariano Pescador. ${ }^{31}$ También se describía el sepulcro del I duque de Montemar, al que nos hemos referido anteriormente, dispuesto en la pared izquierda de la capilla, y se aludía al cuadro de la "Visitación de Nra Sra", con marco de mármol, ubicado en el muro derecho, una obra pictórica que no había sido referenciada en los inventarios anteriores de 1789 y 1804, lo que impide dar una fecha aproximada y certera de su colocación en la misma. ${ }^{32}$

A continuación, se enumeraron consecutivamente los objetos existentes en el interior de la sacristía de la capilla, comenzando por las obras de orfebrería destinadas al culto, después los textiles y finalmente el mobiliario, sin agruparlos en diferentes apartados, a diferencia de lo dispuesto en los registros de 1789 y 1804. En el caso de las piezas necesarias para la liturgia, a los datos proporcionados en los inventarios anteriores, como el material utilizado o el peso, se añadieron las medidas en centímetros y una explicación más detallada. El primer objeto catalogado, un cáliz "antiguo" de plata sobredorada, que contaba con patena y cucharilla, se referenció con mayor precisión, al igual que sucede en los registros de 1789 y 1804. Fue descrito con "el pie en forma de estrella tiene de relieve los cuatro evangelistas y dos angeles; su arbol con el nudo inferior cuadrado, y otro circular y saliente en el centro, y la sobrecopa trepada con seis querubines", advirtiendo que "es tal vez el mas antiguo del templo, y de estilo gotico".
Una pieza que, según las medidas facilitadas, tenía $25 \mathrm{~cm}$ de alto, $17 \mathrm{~cm}$ de diámetro el pie y $9 \mathrm{~cm}$ de diámetro la copa.

En la sacristía mayor de la basílica del Pilar se encuentra en la actualidad un cáliz que coincide con la descripción del inventario, por lo que consideramos que se trata del mismo vaso sagrado que en el siglo XVIII formaba parte del ajuar litúrgico de la capilla de San Joaquín. ${ }^{33}$ Se trata de un cáliz renacentista, del tercer cuarto del siglo XVI, de plata sobredorada, cincelada y repujada $(24,5 \mathrm{~cm}$ de alto; $17 \mathrm{~cm}$ de diámetro el pie y $9 \mathrm{~cm}$ de diámetro la copa) (Fig. 3). Presenta base hexagonal estrellada, conformada por seis lóbulos con escotadura central en los que se sitúan las figuras repujadas de los cuatro evangelistas acompañados de sus atributos, San Marcos con el león, San Juan con el águila, San Lucas con el buey y San Mateo con el ángel, además de dos figuras aladas con parte de las Arma Christi, en un caso, una columna, y por otro, la cruz, quedando a su vez separados por otros seis picos (Fig. 4). El astil, dividido en sectores, está compuesto en su parte inferior por un gollete cuadrado, decorado con motivos vegetales en sus cuatro frentes y costillas vegetales de fundición en las aristas, al que sucede un nudo bipartito, la parte inferior de manzana y la superior cilíndrica de paredes cóncavas entre anillos volados, enmarcado por sendos cuerpos abalaustrados, todo ello con decoración de elementos vegetales y gallones. La copa acampanada diferencia la subcopa mediante una labor calada formada por una decoración de querubines, guirnaldas, máscaras y elementos vegetales, y una moldura superior con crestería de elementos esquemáticos.

Este vaso sagrado carece de marcas de autor o localidad, si bien advertimos que muestra un gran parecido con el cáliz renacentista de plata dorada procedente de la ermita de Nuestra Señora del Pilar de Bagüés (Zaragoza), que posteriormente fue trasladado a la iglesia parroquial de los Santos San Julián y Basilisa de la misma localidad, si bien este tiene una disposición muy regular, con el gollete perfectamente encajado en el pie, el nudo de jarrón y un astil distinto al de la capilla de San

30 A.C.S.Z., Inventario del Santo Templo Metropolitano de Nuestra Señora del Pilar. Año de 1873, pp. 121-125. Apéndice Documental $n^{\circ} 2$

31 ANSÓN NAVARRO, Arturo; BOLOQUI LARRAYA, Belén, 1982, p. 290. CRIADO MAINAR, Jesús, 2005, p. 167.

32 Ansón fechó la ejecución del cuadro hacia 1781, identificando la autoría del mismo en la persona del artista aragonés Diego Gutiérrez. ANSÓN NAVARRO, Arturo, 2007, p. 89. ANSÓN NAVARRO, Arturo, 2012, p. 62. TARIFA CASTILLA, Mª Josefa, 2018 b, pp. 340-341.

33 Agradecemos a don Ignacio Ruiz, director de Patrimonio Artístico del Cabildo Metropolitano de Zaragoza, a don José María Bordetas, capellán de la Virgen del Pilar y a doña Ester Casorrán, del Archivo Capitular del Pilar, su inestimable ayuda para localizar en esta basílica mariana las piezas de orfebrería litúrgica pertenecientes a la capilla de patronato de los duques de Montemar. 


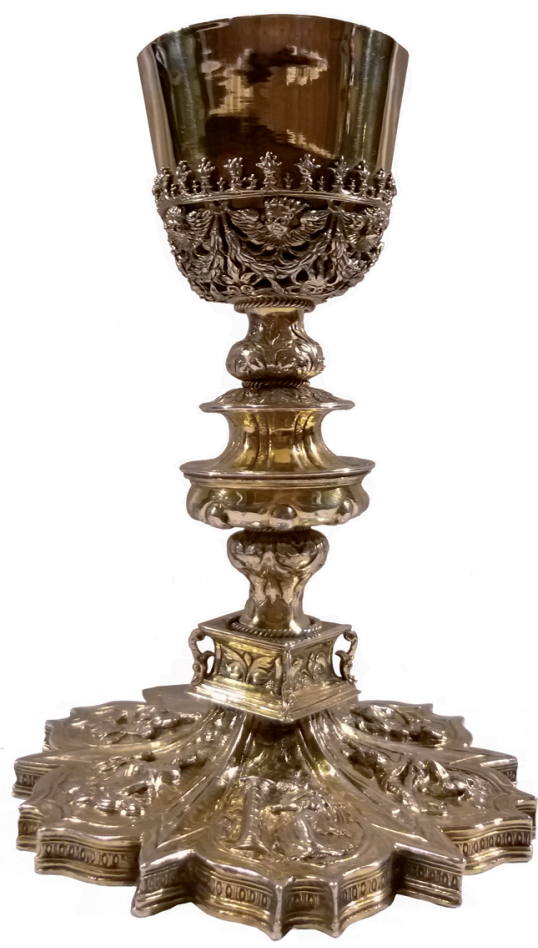

Fig. 3. Cáliz renacentista, tercer cuarto del siglo XVI. Basílica de Nuestra Señora del Pilar de Zaragoza. Fotografía: Ma Josefa Tarifa Castilla. Cabildo Metropolitano de Zaragoza.

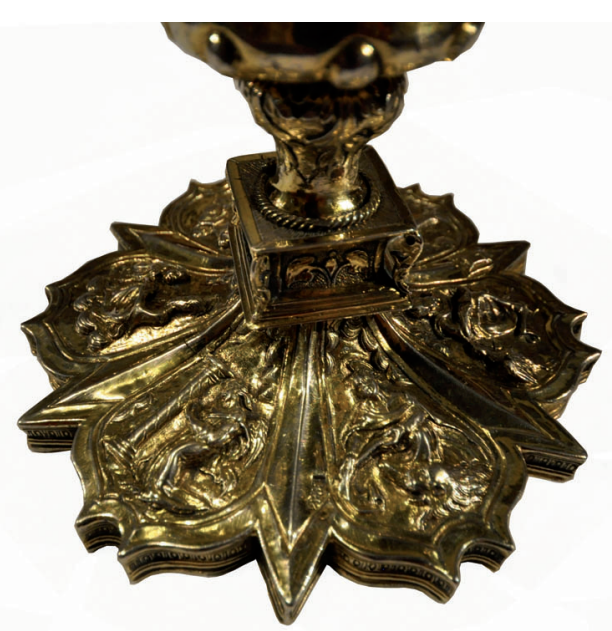

Fig. 4. Cáliz renacentista, tercer cuarto del siglo XVI. Detalle. Basílica de Nuestra Señora del Pilar de Zaragoza. Fotografía: $\mathrm{M}^{\mathrm{a}}$ Josefa Tarifa Castilla. Cabildo Metropolitano de Zaragoza.
Joaquín objeto de estudio. En la actualidad el cáliz de Bagüés $(23 \mathrm{~cm} \times 17 \mathrm{~cm})$ se encuentra junto con una cruz procesional, una custodia y un copón procedentes de la misma ermita, hechos en plata y con punzón de Zaragoza, en una de las dependencias de la catedral de Jaca en la que se depositan otras obras de orfebrería procedentes de la diócesis, el Secretum, formando parte del Museo Diocesano. ${ }^{34}$

El registro de 1873 continuaba con una palmatoria de plata, con el platillo circular formando ondas, con un remate en el asa o mango y un soporte de media caña para sostener la vela, de 33 centímetros de altura en total. También se incluyó la lámpara de plata que colgaba del centro del arco de acceso a la capilla, similar en dimensiones, peso y labor a las veinticuatro lámparas dispuestas en los cuatro frentes de la Santa Capilla, "redondas, cinceladas con tres chapas labradas de plata al arranque de las cadenas" (de $126 \mathrm{~cm}$ de largas, con la copa de $55 \mathrm{~cm}$ de anchura y la campanilla $17 \mathrm{~cm}$ ), pendiendo de todas ellas una borla de seda carmesí. ${ }^{35}$

El listado advertía en una nota que en el registro del templo de 1819 no se había hecho mención a la capilla de San Joaquín, por cuidar de sus enseres la familia de Montemar, y que, además, posiblemente algunos de los ornamentos y objetos pertenecientes a la misma podían haber sido trasladados a la de la parroquia, bajo la advocación de San Agustín, ya que en los nueve años anteriores en los que esta última había permanecido en obras, su culto se había realizado en la capilla de San Joaquín. Por ello, se informó de que en la sacristía mayor del templo se conservaba un relicario de plata, el cual por tener las armas de los Montemar y guardar las reliquias de San Joaquín y Santa Ana, era posible que perteneciese a esta capilla. Efectivamente, en este mismo inventario de 1873 , en el apartado de las alhajas de la sacristía mayor se catalogó con el número 102 un relicario de plata barroco, con las reliquias de San Joaquín y Santa Ana, de $24 \mathrm{~cm}$ de alto y $10 \mathrm{~cm}$ de base, con un peso superior a 8 onzas, en cuyo reverso había sido grabado a cincel el emblema heráldico de los Montemar, por lo que, sin lugar a dudas, la pieza pertenecía al ajuar litúrgico de la capilla cuyo patronato ostentaba la familia de este noble linaje; relicario que también había sido registrado en los listados de 1789 y de 1804, como se ha referido anteriormente.

34 SAN VICENTE, Ángel, 1980, pp. 97-98. LACARRA DUCAY, María del Carmen, 1993, pp. 77-78.

35 A.C.S.Z., Inventario del Santo Templo Metropolitano de Nuestra Señora del Pilar. Año de 1873, p. 31. 
Este relicario lo hemos localizado en la sacristía mayor del templo mariano del Pilar, una pieza de $21 \mathrm{~cm}$ de alto $\times 9,5 \mathrm{~cm}$ de ancho, carente de marcas de localidad y de autor, que ha llegado quebrado por la parte inferior del viril (Fig. 5). Presenta base circular con decoración de rocallas y motivos esquematizados, con el número "102." grabado, al que sucede un estilizado nudo periforme invertido, con una ornamentación de elementos vegetales y rocaIlas acordes a los empleados en la base, que da paso al ostensorio. Este, de perfil mixtilíneo, con un rico juego de curvas y contracurvas, presenta una abigarrada decoración formada por elementos vegetales y rocallas, y dos cabezas de querubines dispuestos en los extremos. A su vez, una guirnalda enmarca el viril central de forma ovalada, en la que se conservan las reliquias de San Joaquín, Santa Ana y San Felipe de Neri, con sus auténticas. Por tanto, se trata de un relicario rococó de finales del siglo XVIII al que en la segunda mitad del siglo XIX se le añadió la base y astil de estilo neorrococó. En definitiva, una pieza que presenta un eje central con un recorrido vertical que divide la obra en dos mitades simétricas. En el reverso del relicario, en la parte posterior del viril se grabaron las armas de los duques de Montemar (Fig. 6), con el mismo emblema heráldico que se dispuso en el arco de embocadura de la capilla de San Joaquín de la basílica del Pilar de Zaragoza. ${ }^{36}$

Por otro lado, en el inventario de la capilla de San Joaquín de 1873 ya no se mencionan algunos de los vasos y utensilios de culto custodiados por el capillero Ripoll en 1839, todos ellos de plata, como un cáliz, un plato con sus dos vinajeras, dos bujías, la cruz de plata con el crucifijo dorado, el hostiario y la campanilla, por lo que es probable que hubiesen sido sustraídos de la sacristía para esta fecha.

Junto a estas obras argénteas, se incluyeron otras piezas que, por el contrario, no habían sido referidas en los inventarios anteriores, elaboradas con metales comunes, como un crucifijo de bronce sobre una cruz de madera negra $(76 \mathrm{~cm}$ de alto $\mathrm{x}$ $29 \mathrm{~cm}$ de ancho), con los extremos del madero, la cartela con el INRI, la calavera y una estrella de bronce. En el momento de realizar este inventario de 1873, también formaba parte del ajuar litúrgico de la capilla de San Joaquín otro crucifijo, en este caso de marfil, de $19 \mathrm{~cm}$ de alto, dispuesto so- bre una cruz de madera negra, con los extremos dorados, la peana en forma de monte y la cartela del INRI labrada sobre una chapa de plata, con una altura total de $67 \mathrm{~cm}$. Sin embargo, tras registrarlo se decidió cambiarlo por el crucifijo existente en la mesa de altar de la Sala Capitular del templo del Pilar, "en razon a lo que ha desmejorado el de marfil de andar de unas a otras sacristias". ${ }^{37}$ El listado alude, también por primera vez, a otras piezas de metal, como dos candeleros de bronce (21 cm alto x $13 \mathrm{~cm}$ de base), además de otros siete candeleros de madera viejos, matizando "que no deben pertenecer a esta capilla"; una "campanilla" de metal antigua $(12 \mathrm{~cm}$ alto x $7 \mathrm{~cm}$ de base), un hostiario de hojalata y tres sacras de madera con cristales, con el marco forrado de "laton trepado", siendo de mayor tamaño la central, de formato apaisado $(35 \mathrm{~cm} \times 44 \mathrm{~cm})$, y las laterales más estrechas $(36 \mathrm{~cm} \times 30 \mathrm{~cm})$.

En el caso de los textiles, se aprecia una disminución considerable de las piezas existentes en los inventarios de 1789 y 1804, tanto en lo referente a la indumentaria eclesiástica como a los ornamentos empleados en el culto de la capilla. En el caso de las casullas, se contabilizaron una docena, algunas de primera clase y otras ordinarias, de distintos colores, blancas, verdes, rojas y moradas, para utilizar en los diferentes tiempos litúrgicos, además de negras, tejidas con diferentes tipos de seda, algunas de damasco y otras de espolín, de las que se detalla además si presentaban galones y cenefas, su decoración y el color del forro de la prenda. La mayor parte de estas casullas tenían la bolsa de corporales y el paño cubrecáliz confeccionados a juego, en cuanto al tejido y el color. También se anotaron cinco albas -una de ellas más elaborada con encaje para el uso de prebendados-, cada una con su fiador o cordón de hilo; cinco amitos -uno de ellos igualmente con puntiIla- y tres pares de cintas de amitos; y cíngulos, uno de seda y los otros dos de hilo. Para el capillero que ayudaba al sacerdote durante el desarrollo de la liturgia, había dos sobrepellices, sin encaje y con cinturones o fiadores de hilo.

Con respecto a los ornamentos de altar, además de las referidas bolsas de corporales y cubrecálices, se encontraron tres manteles con los que revestir la mesa, uno fino con encaje, y otro paño de hilo más

36 RINCÓN GARCÍA, Wifredo, 2009, p. 46.

37 El crucifijo de la Sala Capitular al que se refiere el inventario se describe al hablar de esta dependencia: "La mesa de altar esta con su mantel de retosta bueno con encage fino, hay su atril de bronce, tres sacras de madera con sus cristales, y un crucifijo alto, cuya efigie crecida, pie triangular y cabos de la cruz de nogal, son de bronce dorado a fuego". A.C.S.Z., Inventario del Santo Templo Metropolitano de Nuestra Señora del Pilar. Año de 1873, p. 102. 


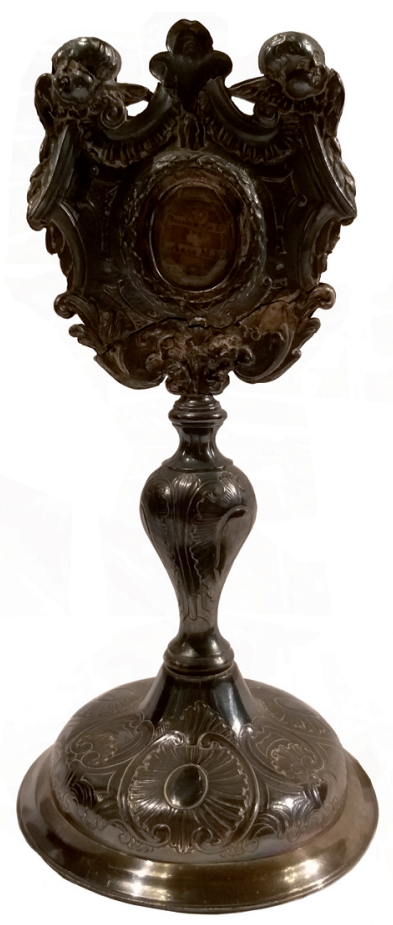

Fig 5. Relicario barroco, siglos XVIII y XIX. Basílica de Nuestra Señora del Pilar de Zaragoza. Fotografía: $M^{a}$ Josefa Tarifa Castilla. Cabildo Metropolitano de Zaragoza.

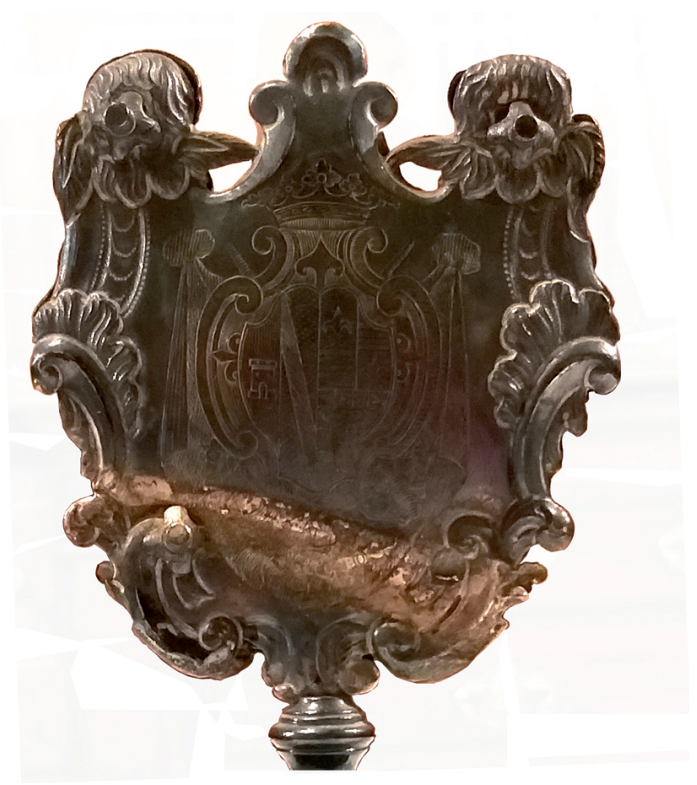

Fig 6. Relicario barroco, siglos XVIII y XIX. Detalle con el escudo de los Montemar. Basílica de Nuestra Señora del Pilar de Zaragoza. Fotografía: Ma Josefa Tarifa Castilla. Cabildo Metropolitano de Zaragoza. pequeño para cubrir el ara del altar; dieciocho purificadores, dos de ellos con encaje en el borde para el uso de señores prebendados; toallas, seis de uso ordinario para el lavabo del altar; "el toallon" con atadores para la sacristía y un paño o rodilla para la limpieza. Por último, se anotó un barreño de hierro y porcelana para contener el agua empleada en el "lababo del altar", es decir, en el rito del lavado de las manos del sacerdote durante el oficio de la misa.

Desafortunadamente, al no conservarse los ornamentos textiles recogidos en el inventario, resulta inviable hacer una valoración más exhaustiva de su confección, posible procedencia o valoración artística, más allá de lo referido anteriormente en cuanto a los tejidos empleados y sus labores ornamentales.

También se inventarió el mobiliario existente en la sacristía de la capilla de San Joaquín, comenzando por una "calajera" o mueble nuevo, de pino, de color nogal $(107 \mathrm{~cm}$ alta x $211 \mathrm{~cm}$ ancha x $91 \mathrm{~cm}$ de fondo), formada por cuatro cajones dispuestos a lo largo y un armario con tiradores dorados y cubierta de gutapercha; otra "calagera" pequeña (110 cm de anchura), de pino y color encarnado, con tres cajones, colocada en el otro extremo de la sacristía; y un tercer armario similar a este segundo mueble y de iguales dimensiones, situado sobre el mismo, con dos puertas, aparadores y un remate tallado. ${ }^{38}$ Asimismo, se anotó un atril de mesa de madera viejo, -sin hacer mención alguna al atril de concha con planchas de plata recogido en los listados de 1789 y 1804-, un misal mediado editado en Madrid en 1808 -que habría sustituido al misal romano impreso en Amberes referido en los registros anteriores-, y un cuaderno de misas de réquiem publicado en Zaragoza en 1848. También se catalogó una tabla con la moldura pintada, "con un impreso de las gracias pontificias a los altares del cuadro". Por último, se menciona el lavatorio de mármol empotrado en la pared de la sacristía, con el frente labrado con jaspes embutidos de distintas tonalidades procedentes de la Puebla de Albortón y el grifo de bronce.

Al igual que en los inventarios de la capilla de los años 1789 y 1804, se alude al retrato de medio cuerpo del I duque de Montemar, pintado al óleo sobre lienzo, con el marco dorado empotrado en la pared, dispuesto sobre una lápida laudatoria de mármol blanco que exaltaba a este distinguido militar, siendo esta la última referencia que hemos localizado de la existencia de dicho cuadro

${ }^{38}$ El mobiliario que en la actualidad se conserva en la sacristía de la capilla de San Joaquín es moderno. 
en la capilla, que como se ha referido anteriormente pintó Juan Andrés Merklein para 1779, cuyo paradero se desconoce en la actualidad. En cambio, no se menciona la pintura que reproducía el rostro de la cara de Dios conservada en la catedral de Jaén, registrada en los inventarios de 1789 y 1804 , de la que no hemos obtenido más noticias, por lo que desconocemos la fecha en la que dejó de formar parte los bienes existentes en la sacristía de esta capilla.

En definitiva, noticias que permiten conocer el ajuar litúrgico con el que los duques de Montemar proveyeron la capilla de San Joaquín de la basílica del Pilar de Zaragoza en el siglo XVIII, principalmente a través del especial empeño de María Magdalena Carrillo de Albornoz, quien por expreso deseo la vinculó al mayorazgo y título del ducado de Montemar. ${ }^{39}$ Ornamentos textiles y piezas de orfebrería que contribuyeron a dotar de mayor magnificencia el culto divino, dignificando las ceremonias sagradas celebradas en esta capilla.

\section{Bibliografía}

ÁGREDA PINO, Ana. Los ornamentos en las iglesias zaragozanas: siglos XVI-XVIII. Aportaciones al estudio de los talleres de bordado y de las artes textiles en Aragón en la Edad Moderna. Zaragoza: Institución Fernando el Católico, Diputación de Zaragoza, 2001.

ALONSO DE CADENAS Y LÓPEZ, Ampelio; CADENAS Y VICENT, Vicente de. Elenco de grandezas y títulos nobiliarios españoles. Madrid: Hidalguía, 1993.

ANSÓN NAVARRO, Arturo; BOLOQUI LARRAYA, Belén. "Zaragoza barroca". En FATÁS, G. (dir.). Guía Histórico-artística de Zaragoza. Zaragoza: Delegación de Patrimonio Histórico-Artístico, Ayuntamiento de Zaragoza, 1982, pp. 221-296.

ANSÓN NAVARRO, Arturo. "Los frutos del brillante magisterio de Francisco Bayeu: sus principales discípulos". En: ANSÓN NAVARRO, A. (com.). Francisco Bayeu y sus discípulos. Zaragoza: Cajalón, 2007, pp. 71-109.

ANSÓN NAVARRO, Arturo. Los Bayeu, una familia de artistas de la llustración. Zaragoza: Caja Inmaculada, 2012.

BOLOQUI LARRAYA, Belén. Escultura zaragozana en la época de los Ramírez, 1710-1780. 2 vols. Madrid: Ministerio de Cultura, 1983.

BOLOQUI LARRAYA, Belén; ANSÓN NAVARRO, Arturo. "Catedral basílica de Nuestra Señora del Pilar". En: BUESA CONDE, D. J. (dir.). Las Catedrales de Aragón. Zaragoza: Caja de Ahorros de Zaragoza, Aragón y La Rioja, 1987, pp. 243-306.

CRIADO MAINAR, Jesús. "Arte y arquitectura en Tauste". En: PALLARÉS JIMÉNEZ, M. A. (coor.). Tauste: agua y vida. IX Centenario de la Villa al Reino de Aragón. Tauste: Ayuntamiento, 2005, pp. 142-179.

ESCRIBANO BERNAL, Francisco. "El duque de Montemar, un Gran Capitán del siglo XVIII". Armas y Cuerpos, 2018, n 139 , pp. 89-94.
FELICES DE LA FUENTE, $\mathrm{M}^{\mathrm{a}}$ del Mar. Condes, marqueses y duques: biografías de nobles titulados durante el reinado de Felipe V. Madrid: Doce Calles, S.L., 2013.

LACARRA DUCAY, María del Carmen. Catedral y Museo Diocesano de Jaca. Zaragoza: Ibercaja, 1993.

MARÍAS, Fernando. "Definición y límites del mecenazgo: en singular, dual y plural, con la basílica del Pilar al fondo". En: IBÁÑEZ FERNÁNDEZ, J. (ed.). Del mecenazgo a las nuevas formas de promoción artística: actas del XIV Coloquio de Arte Aragonés. Zaragoza: Prensas de la Universidad de Zaragoza, 2017, pp. 108141.

MARTÍNEZ ROJAS, Francisco Juan. "Santo Rostro". En: SERRANO ESTRELLA, F. (ed. y coor.). Cien obras maestras de la Catedral de Jaén. Jaén: Universidad de Jaén, Cabildo de la Catedral de Jaén, 2012, pp. 14-17.

RINCÓN GARCÍA, Wifredo. Heráldica en la Basílica de Nuestra Señora del Pilar de Zaragoza. Madrid: Real Academia Matritense de Heráldica y Genealogía, 2009.

SANZ DE MIGUEL, Carlos. "El Mausoleo del I Duque de Montemar en el Pilar de Zaragoza: un encargo de Carlos III en honor a su memoria", Cuadernos dieciochistas, 2018, vol. 19, pp. 213-243.

SAN VICENTE, Ángel. Exposición de orfebrería aragonesa del Renacimiento: catálogo, Zaragoza, del 29 de marzo al 5 de mayo de 1980. Zaragoza: Museo Camón Aznar, 1980.

TARIFA CASTILLA, Ma Josefa. "La inmortalidad de la fama póstuma frente al paso del tiempo: el mausoleo del primer duque de Montemar en la Basílica de Nuestra Señora del Pilar de Zaragoza". En: CASTÁN, A.; LOMBA, C.; POBLADOR, Ma P. (eds.). El Tiempo y el Arte. Reflexiones sobre el gusto IV. Zaragoza: Institución Fernando el Católico, 2018 a, pp. 645-656.

TARIFA CASTILLA, Ma Josefa. "La capilla de San Joaquín de la Basílica del Pilar de Zaragoza bajo el patronato de los Duques de Montemar". Artigrama, 2018 b, n 33, pp. 325-346.

\section{Apéndice Documental}

\section{Documento $n^{\circ} 1$}

\section{Zaragoza, 20 de febrero de 1789}

Inventario de muebles, alhajas, jocalias, ropa blanca, plata y otros objetos existentes en la capilla de San Joaquin del templo del Pilar de Zaragoza.

Archivo Histórico de la Nobleza, Baena, C.364, D.42-60.

En el nombre de Dios Amen. Sea a todos manifiesto que Dn Manuel de Bellostas, Abogado de los Reales Consejos y vecino de la presente ciudad de Zaragoza, asistido de mi el essno de S.M. y del Colegio de Sn Juan Evangelista, se ha constituido en la tarde de este dia en el Sto Metropolitano Templo de Nuestra $S^{a}$ del Pilar y Sachristia de la Capilla de Sn Joaquin, propia de la Exma $S^{a}$ Duquesa de Montemar y sus descendientes, y como Apoderado que es de su ex en virtud del poder otorgado a su fabor en la villa y Corte de Madrid a trece de diciembre de mil setecientos ochenta y ocho, y por Alfonso de Yebenes,

39 A.H.P.M, Felipe de Estepar, año 1790, tomo 24835, f. 541v. 
essno de S.M. y del Colegio de la misma recivido y testificado y se halla en publica y fe faciente forma, legalizado y sellado que me ha exivido y mostrado a mi el dicho essno (de todo lo qual doy fe) hallando ser presentes Mos. Juan Blas Therren y Piran, Presbitero capellan de la dicha capilla que a sido nombrado por dicha Exma $S^{a}$ y Antonio Carbonel, capillero, requirio a este dicho Dn Manuel de Bellostas como tal Apoderado pusiese de manifiesto todos los muebles, alaxas, jocalias, ropa blanca, plata y demas que existe en dicha Sachristia, para tomar razon e imbentario de unas y otras cosas, y resulte formalmente de ello, y a su seguida cumpliendo dicho Carbonel con el seguimiento exivio y manifesto lo siguiente:

Llabes. Primeramente, una llabe que era para el rexado que havia en dcha capilla. Otra para la puerta de la Sachristia. Otra para los calages de la ropa blanca, otra para los demas ornamentos. Otra para un almario que ay al lado derecho de la mesa altar. Otra que por un lado es de la puerta de la Sachristia y por el otro de uno de los tres caxones de ella, la que tenia Mos. Juan Lazaro, ya difunto, y se ha entregado a Dn Juan Blas Terren, actual capellan.

Alaxas de madera en la capilla. Una tarima o gradicula de madera labrada para delante del Altar. Un contramarco ancho moldeado pintado de color de jaspe. Una mesita pintada y dorada para poner las vinageras y servir el Altar.

En la Sachristia. Una tablita de nogal para la gallofa. Una cagita de Aro de cedazo. Un banco nuebo de madera dada de color de nogal. Una mesa grande dada del mismo color con tres calages, y encima tiene su Armario con sus puertas de lo mismo. Una percha dada en el mismo color con sus colgadores. Un tornillo curioso para las toallas de manos con remates de nogal labrado. Una escala de madera de catorce quartas de larga. Un atril de madera dado de color de nogal. Un juego completo de sacras con su lababo y evangelio de talla plateada y bruñida con su Christo plateado al remate de ellas. Dos candeleros pequeños plateados y lisos.

Alajas de barro y otras. Un cantaro grande bidriado para tener el agua. Un barreño para el pie del Altar. Una jarra ordinaria. Un platillo de Aranda con un par de vinageras de christal y tapes de lo mismo. Un ostiero de oxalata para diario y tintero de lo mismo para la misma Sachristia. Dos esteras nuebas, una para la misma sachristia y otra para el Altar. Una campanilla de metal para diario. Un misal grande de impresion de Antuerpia enquadernado en pasta con sus manecillas y rexistros y contraforros de tafilete o badana colorada y otra negra. Un quaderno con cubiertas negras para las misas de requien.

Alaxas de ropa blanca. Seis juegos de manteles de mesa altar de buen uso, los cinco con encage, y el otro sin el. Nueve Albas, las dos con encage mui ancho y las siete restantes regulares, quatro de ellas son casi nuebas y las demas de buen uso. Dos Roquetes guarnecidos de encage para el uso del Capillero.
Item ocho juegos de Corporales guarnecidos de encages, unos mas finos que otros, con tres hijuelas pequeñas de lo mismo para el sobre caliz, y dos de seda con galoncito de oro y campo colorado. Catorce amitos correspondientes a las telas de las Albas, con tres juegos de cintas. Doce toallicas de vinagera. Quatro toallas grandes de manos para la sachristia. Treinta y dos purificadores. Dos cingulos de ilo blanco fino de Genoba. Un saco de estopa y cañamo para llebar la ropa a la colada.

Alaxas de seda. Tres cingulos de seda de diferentes colores. Diez juegos de casullas completos, los cinco de damasco nuebo de los cinco colores precisos, encarnado, blanco, berde, morado y negro con sus estolas, manipulos, velos para cubrir el caliz y tres bolsas de corporales de lo mismo que hacen a todos colores, guarnecidas las dichas cinco casullas con galon de seda fina color de oro y entreteladas en osuna y forradas en olanda, de color de oro, y los velos en tafetan blanco guarnecidos con puntilla fina de oro al ayre con tres palias, la una de estofa de oro y las otras dos de damasco berde y colorado; y los otros cinco juegos de casullas completos, el uno de espolin de seda en fondo blanco con flores de varios colores y guarnicion de galon de oro fino con su velo, y bolsa de corporales de lo mismo, con un frontal de dicha tela y galon para el altar; el otro juego de raso blanco bordado de seda y oro con su galon de oro bordado con su velo, y bolsa de corporales. Otro juego de espolin de seda en fondo de color de puro y varias flores guarnecida con galon de oro con su velo y bolsa de corporales. Otro juego de campo colorado con flores de plata y una faxa en medio de la casulla de seda de color de ambar con su velo y bolsa de corporales. Otro juego de terciopelo negro con su velo y bolsa de corporales guarnecido todo con galon de oro fino. Una casulla berde de mure de aguas guarnecida con un galoncillo de oro fino, cenefa bordada de oro fino a rramos, su velo y bolsa tambien bordados en la misma forma. Otra casulla de raso blanco con su cenefa de espolin de oro y en el unos ramitos azules bordados y en lo demas de ella unas ondas del mismo espolin con iguales ramos dentro, y otros mayores en el centro de las ondas, y todo al extremo un galon de plata con esterilla en medio de oro, y tiene tambien su velo y bolsa de corporales correspondiente. Otra casulla morada con restaño de plata y galon de plata al canto de ella, y su cenefa es toda un bordado de flores tambien de plata y velo y bolsa correspondiente. Otra casulla morada con restaño de plata, y cenefa de la misma tela, guarnecida con galocinto de plata con su velo correspondiente. Un frontal de lienzo pintado que hace a todos colores y una cortina de olandilla para cubrir el altar.

Alaxas de plata. Un caliz de plata lisa con su copa y patena de lo mismo, pero dorada y de peso veinte y quatro onzas y doce adarmes, con su caxa colorada. Una cucharita de plata para poner el agua en el caliz, con su cinta. Una palmatoria de plata de la ulti- 
ma moda de peso de ocho onzas y doce adarmes. La lampara de plata que ay en la capilla de peso de ciento y veynte y cinco onzas bien cumplidas. Una cruz grande de plata con su pie de lo mismo y un Christo de bronce dorado, su peso cincuenta y seis onzas y quatro adarmes. Un ostiero con su tape todo de plata y grabado, con peso de ocho onzas y seis adarmes. Una servillita de plata grabada con peso de siete onzas y quatro adarmes obalada. Un par de vinageras de plata labrada bastante grandes. Una campanilla de plata grabada con peso de once onzas y seis adarmes. Un caliz de plata grabado y labrado con sus efigies al pie de medio reliebe de los evangelistas y otras, y labor colada (sic) por junto a la copa, todo dorado, con su correspondiente patena, de peso de treinta y quatro onzas menos dos adarmes, metido en su caxa colorada y con su cucharita de plata y con cinta de color de rosa seca.

Otras alajas. Seis candeleros grandes de madera mui tallada y plateada. Un platillo obalado y labrado bastante grande de peltre fino de Ynglaterra con su par de vinageras de lo mismo. Un Alba mui rica de musulina de flores con encage de bara de ancho muy esquisito de Flandes, con otros mas angostos y finos en cuello, pechera y mangas, con su amito de la misma tela guarnecido con un encagecito y tiene su caxa para tenerla plegada. Un grande pie de madera labrada y plateada para poner la cruz de plata grande arriba expresada. Una reliquia de plata con las de Sn. Joaquin, Sta. Ana y Sn. Felipe Neri que sera de peso como de unas diez onzas y a la espalda de ella ay una chapa con las armas de la Casa de su Ex ${ }^{a}$ y todo con su caxa forrada en badana encarnada. Un atril de concha con sus planchas de plata. Una efigie de la Cara de Dios de Jaen, con su christal, guarnecido el quadro en moldura azul con sobrepuestos de plata, tiene su caxa de madera forrada en bayeta colorada para su guarda. Tambien ay en dicha Sachristia un Retrato del Exmo. Sr. Duque de Montemar con su marco dorado, y la inscripcion en piedra de marmol vajo del mismo, y se hallan encarcelados en la pared, y tambien en el lavatorio que es de piedra jaspe con rebutidos; y dicho Carbonel capillero dijo que en las casas de la Excma. Sa viuda del Exmo. Sr. D. Miguel Lopez Fernandez de Heredia, existe una alfombra grande de diferentes colores, la que se pone en la Capilla el dia de Sn. Joaquin, pues no ay donde poderla tener en la sachristia. $Y$ assi manifestados todos los referidos muebles, alajas, jocalias, ropa blanca, plata y demas que resulta de parte de arriba y hecho dicho imbentario formal, hizo entrega de todo el expresado Dn. Manuel de Bellostas como apoderado de dicha Exma. $S^{a}$ Duquesa, viuda de Montemar, al relacionado Dn. Juan Blas Therrrer y Piran, Presbitero en calidad de capellan de dicha capilla, y de este las recivio para su responsabilidad el nominado Antonio Carbonel como tal capillero que a sido y es con aprobacion de dicha Exma $S^{a}$, y el uno y otro otorgan del recibo de dichos muebles, alajas, jocalias, ropa blan$\mathrm{ca}$, plata y demas espresado en este imbentario para dicha responsabilidad a poca lexitima con las renun- cianciones y devidas y acostumbradas; y dicho Antonio Carbonel despues de lo referido por quedar como queda todo a su cargo, y que es el que a de cuidar y cuida de su custodia y manejo, se obliga con su persona y vienes a responder de todo y de su mayor cuidado, y presento a mas por fianza para la seguridad de dicho capellan a Antonio Carbonel mayor, su padre, labrador, y vecino de esta ciudad, el qual hallandose presente de su buen grado y cierta ciencia dijo se constituia en tal fianza por dicho Antonio Carbonel menor, su hijo, y se obligo por este a que dara buena y puntual razon y cuenta de todo quanto queda notado en el imbentario de parte de arriba, y que en su defecto lo hara el, como su fiador, a cuyo cumplimiento se obligo su persona y vienes assi muebles como sitios havidos por haber donde quiere; de las quales cosas de instancia y requirimiento de dicho $\mathrm{Dn}$ Manuel de Bellostas, como apoderado de dicha exma. $S^{a}$ Duquesa viuda de Montemar, hice y testifique el presente acto publico. Hecho fue lo sobre dicho en la ciudad de Zaragoza a veinte dias del mes de febrero del año contado del Nacimiento de Nuestro Señor JesuChristo de mil setecientos y ochenta y nuebe, siendo a ello presentes por testigos Mos. Joaquin Palacin Presbitero, y Dn. Ignacio Moliner clerigo tonsurado y musico del dho Sto. Templo, residentes en esta ciudad. Esta continuado y firmado el presente acto publico en la nota original a que me refiero.

Signo de mi Ramon Castel, essno. de su Magd y el colegio de Sn Juan Evangelista de la ciudad de Zaragoza a lo sobre dicho presente fui y signe et cerre.

\section{Documento $\mathrm{n}^{\circ} 2$}

\section{Zaragoza, 1873}

Inventario de la capilla de San Joaquín en el templo de Nuestra Señora del Pilar de Zaragoza.

Archivo Capitular de la Seo de Zaragoza, Inventario del Santo Templo Metropolitano de Nuestra Señora del Pilar. Año de 1873, pp. 121-125.

\section{/p. 121/ Capilla de San Joaquin.}

El vistoso Retablo de esta Capilla, que es de madera dorado y tallado, perteneció a la Iglesia de Religiosos franciscos de la villa de Tauste, trasladado aqui por orden del Prelado como los otros que se han traido de conventos por los años de 48 a 52. Llena este todo el hueco del arco y consta de dos cuerpos. Sobre el basamento general y mesa altar cuyo frontal es de marmol, y pedestales con un sagrario circular de dos puertas, y debajo otro sagrarito, está el cuerpo principal de tres columnas istriadas a cada lado y entre ellas las estatuas al natural de S. Geronimo con traje cardelalicio y San Luis Rey de Francia. En el centro un medallon pintado al temple en que se destaca San Joaquin llevando de la mano a la Stma Virgen (ambos /p. 122/ de cuerpo entero sobre una repisa) y en ademan de subir al templo. El $2^{\circ}$ cuerpo es en el centro un medallon de altos relieves con Jesus y Maria y San Francisco de Asis concedien- 
dole el privilegio de la Porciuncula, dos columnas a cada lado y dos santos obispos entre ellas, de San Luis, Obispo de Tolosa, y San Liborio; y dos angeles sentados en las esquinas de la cornisa del primer cuerpo. Los dos costados igualmente estan adornados de pilastras y rosetones de hieso; en el del Ebangelio sobre un alto zocalo de marmol de la puebla esta la urna cineraria del Duque de Montemar D. Jose Carrillo de Albornoz general y Ministro de Carlos $3^{\circ}$ victorioso en Oran y en las dos Sicilicas, cuya descripcion aparece en una gran lapida de marmol blanco sobre la urna y obelisco que la corona, con dos estatuas a los lados, de estuco que representan la Justicia y el Valor, y trofeos militares. En medio del otro costado hay un cuadro de la Visitacion de Ntra Sra con marco de marmol, bajo el que esta la puerta de la sacristia de nogal tallado.

1. Caliz antiguo de plata sobredorada: el pie en forma de estrella tiene de relieve los cuatro evangelistas y dos angeles; su arbol con el nudo inferior cuadrado, y otro circular y saliente en el centro, y la sobrecopa trepada con seis querubines. Es tal vez el mas antiguo del templo, y de estilo gotico: de 25 centimetros de alto, 17 de diametro el pie y 9 la copa. Tiene su patena y cucharilla, y pesa todo junto 36 onzas. La patena es de 15 centimetros de diametro.

2. Palmatoria de plata, con media caña para la bela, el circulo formando onditas y con remate en el mango. Es larga 33 centimetros y pesa solo cinco onzas.

3. Crucifijo de bronce en cruz con su pie de madera negra con los cabos, inri, calavera y una estrella todo tambien de bronce es alto 76 centimetros por 29 el transversal.

4. Crucifijo de marfil de 19 centrimetros de estatura, sobre cruz de madera negra y cabos dorados y su pie en figura de monte; el inri de chapa de plata. Su altura de pie y cruz 67 centimetros. = Se ha cambiado al hacer este inventario este crucifijo por el de la mesa altar de la Sala Capitular descrito a la pagina 102, en razon a lo que ha desmejorado el de marfil de andar de unas a otras sacristias.

/p. 123/5. Tres sacras de madera con cristales, cuyos marcos son forrados de laton trepado, la del centro apaciada de 44 centimetros ancha, y las latelares de 30 , y sus alturas de 35 y 36 .

6. Misal mediano y en regular uso, con cubiertas royas, edicion de Madrid año 1808.

7. Cuaderno de Misas de Requiem, en pasta, nuevo, edicion de Zaragoza año 1848.

8. Atril de mesa altar de madera viejo.

9. Candeleros, dos de bronce de pie ancho redondos, altos 21 centrimetros por 13 de base; y otros siete candeleros de madera viejos, que no deben pertenecer a esta capilla.

10. Campanilla de metal antigua de 12 cent. alta por 7 de base.

\section{Hostiero de hojalata.}

12. Dos casullas de $1^{\text {a }}$ clase blancas, iguales las dos de espolin con ramos de seda y oro, nuevas; con galones de oro anchos, forro de ruan oro. Hay bolsa y cubrecaliz, este con puntilla de oro.

13. Casulla unica ordinaria blanca de damasco antiguo y cenefa nueva, con galon de seda amarilla y forro de ruan azul. Hay dos cubrecalices de lo mismo, y la Bolsa de corporales sencilla de damasco de cuatro colores para este, encarnado, morado y negro.

14. Casulla de $1^{\text {a }}$ clase encarnada, de espolin antiguo de ramitos de oro con azul, ya trabajada, galon de oro, y forro ruan azul. Tiene solo cubre caliz.

15. Dos casullas encarnadas ordinarias de damasco y galon amarillo; la una tiene cenefa de terciopelo carmesi. Hay solo un cubrecaliz, y estan forradas de ruan azul y pagizo.

16. Dos casullas moradas; la una de espolin de ramos blancos y galon pagizo, con forro de ruan oro; y la otra nueva de damasco violeta galon mas ancho amarillo y forro ruan morado. Hay un cubrecaliz igual a la segunda.

17. Dos casullas verdes, una de espolin arrasado y flores blancas y doradas, con trencilla estrechita vieja de oro, y forro ruan rojo; y la otra de damasco nuevo antiguo con igual galon, y un poco mas ancho en la cenefa, forrada de ruan color plata. Hay un cubrecaliz.

/p. 124/ 18. Dos casullas negras de damasco; la una antigua galon pagizo, forro de ruan rojo; y la otra nueva con galon ancho amarillo y forro ruan negro. Hay un cubrecaliz como esta ultima.

19. Cingulos, uno de seda y dos mas de hilo todos de color blanco y encarnados.

20. Cintas de amitos, tres pares, buenas, el uno verdes $y$ anchas y los otros dos juegos encarnadas.

21. Albas, cinco: la una de señores prebendados con encaje ancho (de 40 centimetros) de hilo, y las otras cuatro ordinarias, todas con sus fiadores de hilo.

22. Amitos, cinco: el uno con encage alrededor para sres, y los otros ordinarios sin el.

23. Manteles, tres: uno fino con encage. Ademas otro paño de hilo para cubrir la lapida o ara.

24. Purificadores, diez y ocho, dos de ellos con encage alrededor para sres; los demas sin el.

25. Toallas siete: seis de ellas ordinarias para el lababo del altar, y la otra el toallon con atadores para la sacristia.

26. Dos sobrepellices para el capiller sin encage, con fiadores de hilo.

27. Una rodilla.

28. Barreño de hierro y porcelana para el agua del lababo del altar. 
29. Calajera nueva de pino color de nogal (de dos metros y 11 centimetros de ancha, y 91 de fondo, por un metro y 7 centimetros de alta), compuesta de cuatro cajones a lo largo y un armario a un lado, con tiradores dorados. Tiene cubierta de gutapercha.

30. Calagera pequeña en el estremo opuesto de la sacristia, de pino y color encarnado, con tres cajones (es un metro, $10 \mathrm{~cm}$ ancha).

31. Armario de lo mismo encima de esta calagera con dos puertas y aparadores, de igual dimensiones, y un remate tallado.

32. Cuadro con marco dorado fijo en la pared, con el Retrato en Busto del Duque de Montemar, pintado al oleo en lienzo, de 65 centimetros alto por 57 de ancho. = Debajo en una lapida empotrada en la pared, que es de marmol blanco, hay una inscripcion de que este Sr. Duque D. Jose Carrillo de Albornoz /p. 125/ Esquivel y Guzman, fue Grande de España, Caballero del Toison de oro, de la Rl. De San Genaro, Comendador de Santiago, Gentil hombre, Director gral de la Caballeria, castellano perpetuo de Caste Novo, consejero de Estado de Napoles, Capital Gral de los Egercitos, Virey de Sicilia, Ministro de Guerra, Decano del Consejo Real, Coronel de las Reales Guar- dias, haber servido a S.M. 65 años y pide que le encomienden a Dios (Murio a 26 de junio de 1747).

33. Labatorio de marmol en la pared con su grifo de bronce, y pila del mismo marmol de la Puebla.

34. Tabla con moldura alrededor pintada, con un impreso de las gracias pontificias a los altares del cuadro (de $46 \mathrm{cms}$ por 94 ).

Nota. En el Inventario de 1819 no se hace mencion de esta capilla, sin duda por cuidar de sus enseres la familia de Montemar. Aunque hoy dia no esten sobradas las capillas, es posible que hayan sido trasladados algunos ornamentos y efectos de esta, a la de la Parroquia con motivo de haber estado esta en San Joaquin los nueve años que han durado las obras, y haber vuelto a la propia suya de San Agustin en octubre ultimo. Hoy la sacristia mayor cuida de todo lo necesario en la presente.

Otra. La Lampara que hay de plata colgada en el centro de la entrada de la capilla, ya se halla incluida en la pagina 31.

Otra. En la sacristia mayor hay un relicario de plata comprendido en este Inventario bajo el num ${ }^{\circ} 102$, en la pagina 22, el cual por llevar las armas de los condes de Montemar y contener Reliquias de San Joaquin y Sta Ana, es posible que pertenezca a esta capilla. 